\title{
EFFECT OF HEALOL OIL ON WOUND HEALING IN WISTAR RATS: A NOVEL STUDY
}

\author{
SUJITH V ${ }^{1}$, POORNIMA G ${ }^{1}$, BALAJI $0^{2}$, BAIRY K L ${ }^{3 *}$, PRAVEEN SE ${ }^{4}$, SOMAYAJI N ${ }^{5}$ \\ ${ }^{1}$ Department of Kasturba Medical College, Manipal University, Manipal, Karnataka, India. ${ }^{2}$ Department of Pharmacology, Kasturba \\ Medical College, Manipal University, Manipal, Karnataka, India. ${ }^{3}$ Department of Pharmacology, RAK College of Medical Sciences, RAK \\ Medical and Health Science University, Ras Al Khaimah UAE. ${ }^{4}$ Department of Pharmacology, Kasturba Medical College, Manipal University, \\ Manipal, Karnataka, India. ${ }^{5}$ Department of Anatomy, Melaka Medical College, Manipal University, Manipal, Karnataka, India. \\ Email:kl.bairy@gmail.com
}

Received: 21 October 2017, Revised and Accepted: 30 November 2017

\section{ABSTRACT}

Objective: Wound healing is a complex process, and various plant extracts have been used to study the effect of medicinal plants on wound healing. Healol oil is used in some tribal areas for ulcer healing and treatment of burn wounds. There are no animal studies done so far using healol oil to find out its role in the treatment of wounds. Hence, the aim of our study is to find the effect of healol oil in excision as well burn wounds in Wistar rats.

Methods: Thirty-six Wistar rats were used, 18 rats in excision wound model and remaining in burn wound model. Each model consists of three groups of six rats each. Povidone-iodine was used as a standard control in excision wound model and silver sulfadiazine was used as a standard control in burn wound model. Healol oil was used as test drug in both the models. Period of epithelization and wound contracture rates were analyzed. Histopathological analysis of the skin tissue was done. One-way analysis of variance was used followed by Tukey's post hoc test for statistical analysis using SPSS version 23 software, $P$ value of $<0.05$ was taken as statistical significance.

Results: Both standard and test groups showed significantly faster wound healing $(\mathrm{p}<0.001)$ compared to control rats treated with paraffin wax in both the models. In excision model standard povidone was significantly $(\mathrm{p}<0.001)$ better compared to healol oil whereas in burn model, silver sulfadiazine and healol oil showed comparable results with respect to period of epithelization without statistical significance $(p>0.05)$.

Conclusion: Wound healing property of healol oil is proved, and further clinical trial can be done to find out the effect of healol oil on chronic wounds due to various etiologies.

Keywords: Healol oil, Burn wounds, Epithelization, Wound contracture.

(c) 2018 The Authors. Published by Innovare Academic Sciences Pvt Ltd. This is an open access article under the CC BY license (http://creativecommons. org/licenses/by/4. 0/) DOI: http://dx.doi.org/10.22159/ajpcr.2018.v11i3.23223

\section{INTRODUCTION}

Wound healing is a multifactorial biological process which is vital to maintain the integrity of the skin and to maintain homeostasis of the body. It is predominantly categorized into three phases: Inflammatory phase, proliferative phase (granulation, wound contraction, and epithelization), which is the center of this study, and finally the remodeling phase leading to scar formation. Healing of the wound can be affected by various factors such as depth, size, location, age of the patient, nutritional status, and medications [1].

Studies have shown the effective use of certain ayurvedic products in enhancing the process of healing. Ayurveda is based on organic substances which can be used medicinally. One such local drug, healol is folklore medicine for the management of ulcers and burn wounds in some tribal areas.

Healol oil is a combination of different plant extracts, namely, $100 \mathrm{mg}$ of Operculina turpethum, $100 \mathrm{mg}$ of Azadirachta indica, $100 \mathrm{mg}$ of Ficus benghalensis, $100 \mathrm{mg}$ of Curcuma longa, $100 \mathrm{mg}$ of Acacia catechu, and $10 \mathrm{mg}$ of Camphora officinarum [2].

Studies with successful wound healing were noted with all of the above-mentioned plants and plant products when used alone or in combination, externally or internally, for the management of wounds and ulcers. Till date, literature search says no studies have been done using this combination.

Hence, the main aim of this study is to study the effect of the ayurvedic preparation of this combination used topical in excision as well burn wound model in Wistar albino rats and to access the rate of wound healing along with a period of epithelization.

\section{METHODS}

The wound healing studies were carried out after obtaining the Institutional Animal Ethics Committee clearance.

\section{Drugs and materials}

Healol oil, povidone-iodine, silver sulfadiazine, paraffin wax, ketamine, xylazine, and surgical equipment were used.

\section{Animals}

Healthy, inbred, male albino rats of Wistar strain, weighing between 150 and $200 \mathrm{~g}$ were used in the study. They were individually housed and maintained on normal diet (Hindustan Lever rat pellets) and water ad libitum. Animals were periodically weighed before and after the experiments. The animals were randomly distributed into three groups, consisting six animals each in each model (excision and burn model).

- Group 1 - Control (paraffin wax).

- Group 2 - Standard (povidone-iodine for excision model, silver sulfadiazine for burn model).

- Group 3 - Healol oil (test).

After overnight fasting, animals were anesthetized using ketamine+xylazine $(70+7 \mathrm{mg} / \mathrm{kg}$ body weight of rat) intraperitoneally. Electronic clipper was used for clipping the fur. A wound was made on the dorsal aspect of the body of rat near the nape of the neck. Rats showing signs of infection were excluded from the study. 


\section{Wound healing model}

\section{Excision wound model}

A round seal of $2.5 \mathrm{~cm}$ diameter was made on the dorsal intrascapular region, $5 \mathrm{~cm}$ away from the ears of the anesthetized rat. Full-thickness skin from the demarcated area was excised to a get a wound measuring $500 \mathrm{~mm}^{2}$. Healol was applied to the wound from day 0 (day of wounding) to $21^{\text {st }}$ post-operative day or till the wound will heal completely, whichever occurred earlier.

Wound contraction was studied by tracing the raw wound area on a butter paper on every alternate day starting from day 0 (day of wounding) to $21^{\text {st }}$ post-operative day or till the wound healed whichever occurred earlier. The animal was restrained in a proper position during tracing. These tracings were then transferred to a $1 \mathrm{~mm}^{2}$ graph sheets. The wound contraction was calculated as a percentage of the original wound size $\left(500 \mathrm{~mm}^{2}\right)$ taken as $100 \%$ for each animal of the group [3]. The group mean was calculated for predetermined days, namely, $4^{\text {th }}, 8^{\text {th }}$, $12^{\text {th }}$, and $16^{\text {th }}$ day for final analysis of results.

$$
\% \text { of wound contraction }=\frac{\begin{array}{l}
\text { initial wound size }- \\
\text { specific day wound size }
\end{array}}{\text { Initial wound size }} \times 100
$$

Period of epithelialization was monitored by noting the number of days required for the scab to fall away, leaving no raw wound behind.

On $10^{\text {th }}$ post-operative day, granulation tissue from the area was collected using a punch biopsy needle $(5 \mathrm{~mm})$ under ketamine anesthesia, for histopathological analysis

\section{Histopathological study}

Punch biopsy from the excision wound model was fixed under $10 \%$ formalin solution for $24 \mathrm{~h}$ and dehydrated with ethanol. The specimens are embedded in paraffin wax, stained and were evaluated.

\section{Burn wound model}

Partial thickness burn wounds were inflicted on animals starved overnight after ketamine anesthesia, by pouring hot molten wax at $80^{\circ} \mathrm{C}$ into a metal cylinder with $300 \mathrm{~mm}^{2}$ circular opening, placed on the back (nape of the neck) of the animal [3]. The parameters observed in the study were as follows:

1. Epithelialization period: It was monitored by noting the number of days required for the eschar to fall off from the burn wound surface without leaving a raw wound behind.

2. Wound contraction: It was noted by following the progressive changes in wound area planimetrically, excluding the day of the wounding. The size of the wounds was traced on a transparent paper every alternate day, throughout the monitoring period of 21 days. The tracing was then transferred to $1 \mathrm{~mm}^{2}$ graph sheet, from which the wound surface area was evaluated.

The evaluated surface area was then employed to calculate the percentage of wound contraction, taking the initial size of the wound as $100 \%$, using the following equation:

$$
\% \text { of wound contraction }=\frac{\begin{array}{l}
\text { initial wound size }- \\
\text { specific day wound size }
\end{array} \times 100}{\text { Initial wound size }}
$$

Initial wound size

\section{Statistical analysis}

Statistical analysis was performed using one-way analysis of variance followed by post hoc analysis using Tukey's test with the help of SPSS software version 23 . $\mathrm{p}<0.05$ was taken as to be statistically significant.

\section{RESULTS}

The effects of healol oil in excision wound model and burn wound model on wound contraction are tabulated in Tables 1 and 2, respectively. Significant faster wound contraction $(p<0.001)$ than the control group was observed with both the standard as well as test groups in both the models. Epithelization period was significantly faster $(\mathrm{p}<0.001)$ compared to the control group in both standard as well as the test groups in both the models. Wound contraction and epithelialization of healol group were significantly slower $(\mathrm{p}<0.001)$ compared to the standard in excision wound model. Wound contraction was significantly slower $(\mathrm{p}<0.001)$ compared to the standard in burn wound model, but there was no significant $(p>0.05)$ difference in the epithelization period when compared to the standard in case of burn model.

Histopathological analysis was done for both models as shown in Figs. 1 and 2. Both standard as well test groups showed better healing when compared with control. The control group showed subnormal repaired tissue. Epidermis and dermis were not clearly separated. Hair follicles and the muscular tissue are also seen in the primitive stage in the deeper parts with minimal neovascularization. Superficial parts have immature stroma with scanty blood vessels. The standard group showed bundles of connective fibers characteristic of collagen maturation. Neovascularization has taken place, and the blood vessels are clearly seen. More superficial parts of the section show dense population of cells which are closely packed, indicating that the stroma is lacking or yet to form. Distinction between dermis and epidermis was noted. In the healol treated group, there was apparent distinction into epidermis and dermis. Dermis has well developed connective tissue. Cell is clearly distinct with matured collagenous connective tissue. Blood vessels are well developed; glands and the muscular tissues are very clearly seen. Healing is comparable to standard treatment group.

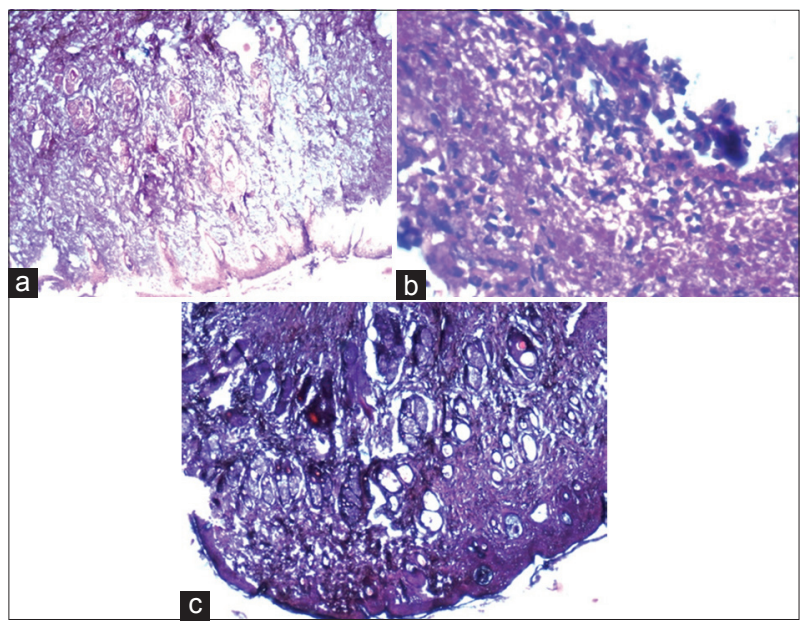

Fig. 1: Histopathology of excision wound model. (a) Control group, (b) standard povidone-iodine, (c) healol oil group

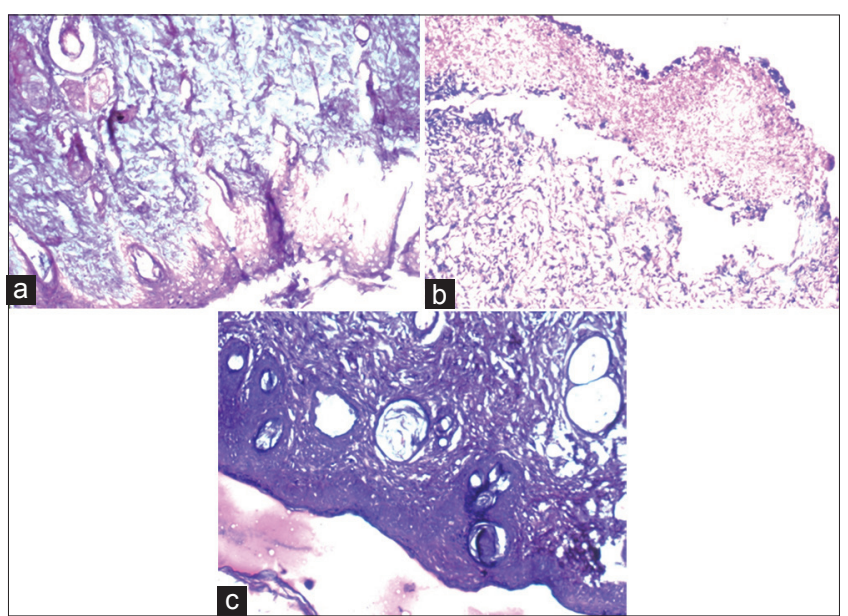

Fig. 2: Histopathology of burn wound model. (a) Control group, (b) standard silver sulfadiazine, (c) healol oil group 
Table 1: Effect of Healol oil on the rate of wound contraction in an excision wound

\begin{tabular}{|c|c|c|c|c|}
\hline \multirow[t]{2}{*}{ Group $(n=6)$} & \multicolumn{4}{|c|}{ Wound contraction $\%$ in mean \pm SEM } \\
\hline & Day 4 & Day 8 & Day 12 & Day 16 \\
\hline Control & $20.98 \pm 0.20$ & $50.56 \pm 0.28$ & $70.78 \pm 1.05$ & $99.55 \pm 0.36$ \\
\hline Test & $17.97 \pm 0.32 *$ & $38.23 \pm 0.47^{*}$ & $69.83 \pm 0.59 *$ & $96.42 \pm 0.50 *$ \\
\hline
\end{tabular}

${ }^{*} \mathrm{p}<0.001$ : Both standard and test group versus the control group. ${ }^{\$} \mathrm{p}<0.001$ : Standard group versus Healol group. Values are expressed as mean \pm SEM. Statistical analysis was done using one-way ANOVA followed by Tukey's post hoc test, $\mathrm{p}<0.05$ taken as statistical significance. SEM: Standard error of mean, ANOVA: Analysis of variance

Table 2: Effect of Healol oil on the period of epithelialization in an excision wound

\begin{tabular}{ll}
\hline Group $(\mathbf{n}=\mathbf{6})$ & Period of epithelialization (days) mean \pm S.E.M \\
\hline Control & $21.00 \pm 0.36$ \\
Standard & $17.11 \pm 0.21 * \$$ \\
Test & $18.66 \pm 0.16^{*}$
\end{tabular}

${ }^{*} \mathrm{p}<0.001$ : Both standard and test group versus the control group. ${ }^{\$} \mathrm{p}<0.001$ : Standard group versus healol group. Values are expressed as mean \pm S.E.M. Statistical analysis done using one-way ANOVA followed by Tukey's post hoc test, $P<0.05$ taken as statistical significance. SEM: Standard error of mean, ANOVA: Analysis of variance

Table 3: Effect of Healol oil on the rate of wound contraction in a burn wound

\begin{tabular}{lllll}
\hline \multirow{2}{*}{ Groups } & \multicolumn{4}{l}{ Wound contraction \% in mean \pm SEM } \\
\cline { 2 - 5 } & Day 4 & Day 8 & Day 12 & Day 16 \\
\hline Control & $21.49 \pm 0.28$ & $40.56 \pm 0.35$ & $60.60 \pm 0.45$ & $81.22 \pm 1.20$ \\
Standard & $15.89 \pm 0.45^{*} \$$ & $35.27 \pm 1.89 * \$$ & $49.49 \pm 1.15 * \$$ & $67.54 \pm 1.89 * \$$ \\
Test & $21.51 \pm 0.66^{*}$ & $35.99 \pm 1.49 *$ & $56.37 \pm 1.19 *$ & $72.86 \pm 1.81^{*}$ \\
\hline${ }^{*}$ p $<0.001:$ Both standard and test group versus the control group. ${ }^{\$}$ p $<0.001:$ \\
standard group versus Healol group. Values are expressed as mean \pm S.E.M. \\
Statistical analysis done using one-way ANOVA followed by Tukey's post hoc \\
test, p<0.05 taken as statistical significance. SEM: Standard error of mean, \\
ANOVA: Analysis of variance
\end{tabular}

Table 4: Effect of Healol oil on the period of epithelialization in a burn wound

\begin{tabular}{ll}
\hline Group $(\mathbf{n}=\mathbf{6})$ & Period of epithelialization (days) mean \pm S.E.M \\
\hline Control & $23.5 \pm 0.42$ \\
Standard & $20.5 \pm 0.32^{*}$ \\
Test & $21.3 \pm 0.16^{*}$ \\
\hline
\end{tabular}

${ }^{*} \mathrm{p}<0.001$ : Both standard and test group versus the control group. Values are expressed as mean \pm S.E.M. Statistical analysis done using one-way ANOVA followed by Tukey's post hoc test, $\mathrm{p}<0.05$ taken as statistical significance. SEM: Standard error of mean, ANOVA: Analysis of variance, ANOVA: Analysis of variance

\section{DISCUSSION}

Epithelialization is the process of restoring the stratified epithelium following injury. This involves migration and proliferation of epithelial cells. The migration is further facilitated by degradation of extracellular matrix in the way of keratinocyte progression by different metalloproteinases. When a layer of epithelial the cell is established, migration and proliferation stops and differentiation of the cell starts to provide stratified epithelium [1]. In our study, we found out that Healol oil has wound healing property and was better when compared with control rats. In case of excision model povidone-iodine was better than Healol oil, but in burn model, epithelization with Healol oil was comparable to standard silver sulfadiazine.
Efficacy of Healol in wound contraction and epithelization period can perhaps be attributed to the combined as well as individual actions of the various organic constituents on the oil. 0 . turpethum has been traditionally used in various parts of India to treat fever, edema, anemia, ulcers, wounds, and other skin disorders [2]. A. indica (commonly called neem) has been in medicinal usage for several decades, chiefly for its activity in wounds, ulcers, leprosy, and jaundice [4]. F. benghalensis (Indian banyan) is being used in several alternative medicinal systems for its efficacy in treating wounds, ulcers, and diabetes mellitus [5]. C. longa (turmeric) is a well-known household remedy for wounds, ulcers, and skin diseases. It has also found a role in cancer chemotherapy and immune stimulation, in ayurvedic practice [6]. A. catechu (commonly called khair) is used in alternative medicine for treatment of hemorrhoids, myalgia, ulcers, and wounds [7].C. officinarum (Camphor) is a vegetable oil that has a strong odor, commonly used to improve the consistency and flavor of ayurvedic products. It is also being used for the management of wounds and ulcers, in addition to treating heartburns and neuralgia [8].

With the backing of various successful studies and their beneficial use since ancient history, the combination of the ingredients in Healol undoubtedly makes for an effective drug when used in wound healing.

\section{CONCLUSION}

Healol oil is found to have an effect on wound healing in rats in both excisions as well as burn wounds. Hence, proper clinical trials can be done to find out the effect of healol oil in treating wounds due to various etiology.

\section{REFERENCES}

1. Diegelmann RF, Evans MC. Wound healing: An overview of acute, fibrotic and delayed healing. Front Biosci 2004;9:283-9.

2. Government of India, Ministry of health and family welfare, Department of ISM and H. The Ayurvedic Pharmacopoeia of India, Part I. $1^{\text {st }}$ ed., Vol. 3. New Delhi, India: Government of India, Ministry of Health and Family Welfare, Department of ISM \& H; 2001. p. 213-4, 404.

3. Pawar RS, Chaurasiya PK, Rajak H, Singour PK, Toppo FA, Jain A, et al. Wound healing activity of Sida cordifolia linn. In rats. Indian J Pharmacol 2013;45:474-8.

4. Kausik B, Chattopadhyay I, Banerjee RK, Bandyopadhyay U. Biological activities and medicinal properties of Neem (Azadirachta indica). Curr Sci 2002;82:1336-45.

5. Patil VV, Patil VR. Ficus bengalensis Linn.-an overview. Int J Pharm Biosci 2010;1:1-11.

6. Witkin JM, Li X. Curcumin, an active constiuent of the ancient medicinal herb Curcuma longa L.: Some uses and the establishment and biological basis of medical efficacy. CNS Neurol Disord Drug Targets 2013;12:487-97.

7. Singh KN, Lal B. Notes on traditional uses of khair (Acacia catechu Wild.) by inhabitants of shivalik range in Western Himalaya. Ethnobotanical Leafl 2006;2006:12.

8. Thakur R, Jain N, Pathak R, Sandhu SS. Practices in wound healing studies of plants. Evid Based Complement Alternat Med 2011;2011:438056 